\title{
El respeto de los principios laborales y el acceso a la justicia en los procesos de empleo público y seguridad social tramitados ante la jurisdicción contencioso administrativa
}

\section{Francisco Hidalgo Rueda \& Irving Vargas Rodríguez ${ }^{2}$}

1. Licenciatura en Derecho de la Universidad Autónoma de Centroamérica, Magíster en Derecho Laboral y Seguridad Social de la Universidad Estatal a Distancia (UNED), Juez en el Tribunal Contencioso Administrativo y Civil de Hacienda, labora en el Poder Judicial. Correo: frankhidalgor@hotmail.com

2. Bachiller en Relaciones Internacionales de la Universidad Nacional (UNA), Licenciatura en Derecho de la Universidad Latina de Costa Rica, Magíster en Derecho Laboral y Seguridad Social de la Universidad Estatal a Distancia (UNED), Juez de Trabajo, Letrado de la Sala Segunda de la Corte Suprema de Justicia, labora en el Poder Judicial.

Correo:ivargasr4@gmail.com

\author{
Recibido: Enero 2015 • Aceptado: Febrero 2015
}

\section{RESUMEN}

En este artículo se exponen y analizan las implicaciones que ha tenido la declaratoria de inconstitucionalidad del artículo 3.a) del Código Procesal Contencioso Administrativo (Ley No 8508 del 28 de abril del 2006, vigente a partir del 1 de enero del 2008, Gaceta $\mathrm{N}^{\circ} 120$ del 22 de junio del 2006), así como del numeral 402.d) del Código de Trabajo (Ley $\mathrm{N}^{\circ} 2$ del 27 de agosto de 1943), mediante los votos de la Sala Constitucional números 9928, de las 15:00 horas del 9 de junio, 11034 de las 14:51 horas, del 23 de junio y 17900, de las 15:00 horas del 27 de octubre, todos del 2010.

Palabras clave: empleo público, acceso a la justicia, principios laborales, jurisdicción contencioso administrativo.

\section{SUMMARY}

This article describes and analyzes the implications that has been declared unconstitutional Article 3 a) of the Code of Administrative Disputes (Act 8508 of April 28, 2006, effective as of January 1, 2008, Gaceta No. 120 of June 22, 2006) and the numeral 402.d) of the Labour Code (Act No. 2 of August 27, 1943), by the votes of the Constitutional Chamber numbers 9928, 15:00 hours June 9, 11034 from 14:51 hours on June 23 and 17900, at 15:00 am on October 27, all of 2010.

Keywords: public employment, access to justice, labor principles, administrative jurisdiction.

\section{Introducción}

Mediante los votos de la Sala Constitucional números 9928, de las 15:00 horas del 9 de junio, 11034 de las 14:51 horas, del 23 de junio y 17900, de las 15:00 horas del 27 de octubre, todos del 2010, se declaró la inconstitucionalidad del artículo 3.a) del Código Procesal Contencioso Administrativo (Ley $\mathrm{N}^{\circ} 8508$ del 28 de abril del 2006, vigente a partir del 1 de enero del 2008, Gaceta 
$\mathrm{N}^{\circ} 120$ del 22 de junio del 2006), así como del numeral 402.d) del Código de Trabajo (Ley No 2 del 27 de agosto de 1943).

Tomando como línea de partida que con anterioridad al dictado de la primera resolución de la Sala Constitucional, en el mes de junio del año 2010, y según la misma pauta marcada por años por la Sala Primera de la Corte Suprema de Justicia, resulta claro que, tal y como se determinó por la Sala Constitucional, el justiciable pudo haberse visto afectado por la propia Administración de Justicia, al no diferenciar qué casos debían ser resueltos por los Tribunales de Trabajo, y cuáles por los Tribunales Contencioso Administrativo, pues simplemente toda materia, tratándose del tema de empleo público y seguridad social, se residenciaba en la vía laboral, con el agravante de la posible falta de especialización de quien juzgaba, al resolver las nulidades de actos administrativos.

Al respecto, es necesario recordar la posición de la Sala Constitucional antes de junio del 2010, en cuanto a la competencia de los jueces y juezas de trabajo relacionado con la anulación de actos administrativo tratándose de asuntos de empleo público o de la seguridad social dictados por la Caja Costarricense de Seguro Social.

Así en el voto número 5686, de las 15:39 horas del 18 de octubre de 1995, ante Consulta Judicial formulada por el Juzgado Primero de Trabajo de San José, citando a la vez la sentencia 3905, de las 15:57 horas del 3 de agosto de 1994, ese alto tribunal señaló que la delegación legislativa al juez o jueza de trabajo tiene la competencia material de revisar la legalidad de algunos actos de la Administración Pública, lo cual no quebranta la Constitución Política en su artículo 49.

Inclusive en la sentencia número 14999, de las 15:06 horas del 17 de octubre del 2007, estando promulgado, y unos meses antes de la entrada en vigencia del Código Procesal Contencioso Administrativo, en acción promovida para declarar inconstitucional la jurisprudencia de la Sala Primera de la Corte Suprema de Justicia que remitía a la jurisdicción laboral el conocimiento de los asuntos cuyo objeto versaba sobre la nulidad por ilegalidad de actos administrativos que tenían como efecto el despido del funcionario o funcionaria pública, así como el artículo 3 inciso a) del Código Procesal Contencioso Administrativo, la Sala Constitucional indicó:

(...) II.- A pesar de esa deficiencia procesal de la acción, en aplicación del principio "pro sentencia", cabe decir que sobre el problema constitucional planteado por el accionante la Sala ha mantenido una línea jurisprudencial unánime, al considerar, que tanto el juez laboral como el juez agrario pueden anular actos administrativos y ha resuelto, concretamente, que no es contrario al artículo 49 de la Constitución Politica la competencia material atribuida a la Jurisdicción Laboral para la anulación de un acto administrativo de despido de un funcionario o funcionaria públicos (v. sentencias número 3905-94 y 5686-95) y, en forma congruente, que la competencia asignada por el artículo 49 de la Constitución a la jurisdicción contencioso administrativa puede ser delegada por la ley en otros tribunales de competencia material distinta, como es el caso de la jurisdicción de Trabajo, que también es una jurisdicción creada por la Constitución (...) La Sala considera, además, que los antecedentes citados tienen como presupuestos de interpretación y aplicación de la Constitución los principios "pro hómine" y "pro operario", así como la mejor garantía para el trabajador-sea funcionario o empleado público-, en tanto que el presunto conflicto constitucional se ha planteado para garantizar la supremacía del artículo 49 constitucional, entendido desde un punto de vista orgánico y competencial, sobre el cual prevalecen aquellos principios inherentes a los derechos fundamentales... (la negrita es propia).

No obstante, el problema se revirtió, pues siendo que, ante lo dispuesto ahora en una nueva línea jurisprudencial por la Sala Constitucional, cuando sean tramitadas nulidades de actuaciones administrativas relacionadas con empleo público y seguridad social y deban ser conocidas en la jurisdicción contencioso administrativa, se presenta el problema que los jueces y las juezas de esa jurisdicción deben resolver los casos aplicando el derecho laboral, sabedores de que no es su especialidad.

Para resolver este paradigma, tal y como lo señaló el Tribunal Constitucional, siendo luego 
reafirmado y explicado por la Sala Primera de la Corte Suprema de Justicia después de junio del 2010, ante conflictos de competencia planteados entre los jueces de trabajo y de lo contencioso administrativo deben incluirse los criterios determinantes para deslindar el ámbito competencial de la jurisdicción contencioso-administrativa de otros órdenes jurisdiccionales especializados -que, en adelante, deben tenerse en consideración por la jurisdicción ordinaria- serán, entonces, los siguientes: $1^{\circ}$ ) El contenido material o sustancial de la pretensión y $2^{\circ}$ ) El régimen jurídico aplicable.

\section{Aplicación de los principios laborales en la jurisdicción contencioso administrativa}

En razón de la declaratoria de inconstitucionalidad del artículo 3.a) del Código Procesal Contencioso Administrativo y del numeral 402.d) del Código de Trabajo cabe cuestionarse si los principios procesales laborales, tales como el de gratuidad, informalidad, oralidad y celeridad, pueden o no ser aplicados por quien juzgue en la jurisdicción contencioso administrativa, al discutirse pretensiones de índole laboral y de seguridad social, cuando existe de por medio una solicitud de nulidad de alguna actuación administrativa, sea, desde la revisión de un despido, presuntamente ilegal, hasta el otorgamiento, la denegatoria, restricción y suspensión de una pensión por invalidez, vejez y muerte.

Esto debido a que los jueces y juezas contencioso administrativos, tienen que conocer de estos procesos luego de la declaratoria de inconstitucionalidad del artículo 3.a) del Código Procesal Contencioso Administrativo y 402.d) del Código de Trabajo, mediante los votos de la Sala Constitucional números 9928, 11034 y 17900, del 2010.

Es importante determinar lo aludido en el párrafo anterior, porque de la respuesta obtenida puede extraerse si a la persona usuaria le están impidiendo o limitando el acceso a la justicia, de conformidad con el ordinal 41 de la Constitución Política. Esto porque en la vía contencioso administrativa, a diferencia de lo que sucede en la laboral, la parte actora debe acompañarse de patrocinio letrado; es decir, todos sus escritos, incluyendo la demanda, deben ir autenticados por un abogado o abogada.

Esto no sucede en los procesos laborales, en los que es innecesaria la autenticación de la firma de la persona trabajadora. Basta con que el escrito sea presentado cumpliendo las formalidades mínimas del artículo 461 del Código de Trabajo, para que se dé curso a la acción. De realizarse alguna prevención en cuanto a la cuantificación de las pretensiones o aclaración de los hechos, por lo general son las mínimas, más que todo, con el ánimo de que el proceso avance sin demora alguna.

Se hace la prevención, pero no con la advertencia de negar el curso a la demanda, sino que el trámite se suspenderá hasta tanto no se cumpla con lo solicitado (doctrina del artículo 462 del mismo cuerpo legal). La materia del derecho del trabajo tiene un alto contenido de justicia social, el cual sin duda alguna, está presente directamente durante la tramitación de todo el proceso laboral. Debe tomarse en cuenta, también, que la persona que trabaja no busca empleo, sino que su fin último es prestar un servicio para ganar un salario, sustento diario de cada familia y del individuo en sí mismo.

El salario como contra prestación por el servicio prestado, tanto ante un patrono privado como para el Estado o alguna de sus instituciones, es un derecho humano, ingreso económico y bastón necesario para el sostén de la familia. Este se alcanza con ocasión del trabajo prestado, y por eso, cuando una persona acude a estrados judiciales, para la cancelación de prestaciones de índole laboral, entre estas el salario, no lo hace pensando en que el solo acceso a la justicia será una limitante, sino más bien, que sus demandas serán escuchadas sin más trámite ni formalidades.

Así lo creyó el constituyente de 1949, cuando instituyó una jurisdicción especializada para este tipo de reclamos, la laboral, y por eso creó en el artículo 70, una jurisdicción de trabajo dependiente del Poder Judicial.

El proceso laboral es tan informal que inclusive los hechos de la demanda, así como las pretensiones, pueden presentarse ad pud acta en los 
despachos judiciales especializados, de forma tal que, en la mayoría de los casos, la persona usuaria se apersona a la oficina judicial en donde será atendida por un técnico o técnica judicial, quien le tomará sus datos personales, consignará los hechos de la demanda y las pretensiones dictadas por la persona, y si cumple con lo mínimo exigido en el artículo 461 del Código de Trabajo, se dará curso a la acción.

Esta situación no ocurre en el proceso contencioso administrativo, donde el numeral 58 del Código Procesal Contencioso Administrativo establece requisitos mínimos de admisibilidad de la demanda, con la consecuente inadmisibilidad de la acción y archivo del expediente si no se cumplen, según lo estatuye el artículo 61 de ese cuerpo normativo.

\section{Tramitación de las demandas de empleo público y seguridad social en la jurisdicción contencioso administrativa}

Antes del mes de junio del año 2010, pese a la discusión, fallos jurisprudenciales y doctrina existente en torno a los temas del empleo público y de la seguridad social, y a la delimitación de las competencias de los tribunales costarricenses, entre las jurisdicciones de lo contencioso administrativo y la laboral, el ordenamiento jurídico costarricense permitía, sin realizar filtro alguno, que todo proceso judicial que tuviera una pretensión relacionada con las materias de empleo público y de la seguridad social, debía ser conocida por los jueces y juezas de trabajo.

Antiguamente el artículo 4 de la Ley Reguladora de la Jurisdicción Contencioso Administrativa $\mathrm{N}^{\circ} 3667$ de 1966, y posteriormente el numeral 3.a) del Código Procesal Contencioso Administrativo, Ley Número 8508 del 28 de abril del 2006, que entró a regir a partir del día $1^{\circ}$ de enero del 2008, regulaban claramente que toda relación de empleo público debía ser del conocimiento de la jurisdicción laboral. Lo anterior no generaba discusión alguna, pues era un precepto legal no cuestionado. Textualmente, el cardinal 3.a) citado disponía: "La jurisdicción Contencioso-Administrativo y Civil de Hacienda no conocerá las pretensiones siguientes: a) Las relacionadas con la conducta de la Administración Pública en materia de relaciones de empleo público, las cuales serán de conocimiento de la jurisdicción laboral."

No obstante, esto cambió con la declaratoria de inconstitucionalidad de la norma transcrita, y posteriormente del numeral 402 inciso d) del Código de Trabajo que establecía:

Los Juzgados de Trabajo conocerán en primera instancia, dentro de sus respectivas jurisdicciones: d. De todas las cuestiones de carácter contencioso que surjan con motivo de la aplicación de la Ley de Seguro social, una vez que la Junta Directiva de la Caja Costarricense de Seguro Social haga el pronunciamiento que corresponda, y siempre que, por la cuantía, tales cuestiones no sean de conocimiento de los Alcaldes...

Lo anterior a través de los votos dictados por la Sala Constitucional, número 9928, 11034 y el 17900 , del 2010, el panorama cambió radicalmente, pues no solo se dispuso la anulación de estos artículos, sino que ahora quien acuda ante la vía jurisdiccional para discutir pretensiones de empleo público y de seguridad social, existiendo de por medio una solicitud de nulidad de alguna actuación administrativa, deberá en primer término delimitar sus pretensiones y así, determinar si debe presentar la demanda en la vía laboral o bien, en la contencioso administrativa, ambas de raigambre constitucional (artículos 49 y 70).

De hacerlo en la jurisdicción laboral, tal y como siempre ha sucedido, el procedimiento se regirá por los principios procesales estructurales y propios de esa vía jurisdiccional, tales como oralidad, celeridad, inmediación, concentración, oficiosidad, gratuidad, inquisitivo y dispositivo.

El principio de gratuidad se materializa o concreta con la eliminación de cargas procesales, como la autenticación del escrito de demanda y el pago de timbres para todos los actos jurídicos, así como la eliminación del formalismo de litigar con patrocinio de un profesional en Derecho y otros más presentes en la jurisdicción contencioso administrativo.

Debe recordarse que el artículo 443 del Código de Trabajo establece que el procedimiento en 
todos los juicios de competencia de los Tribunales de Trabajo es fundamentalmente verbal. Esto significa que la mayoría de las gestiones de las partes, tales como manifestaciones, otorgamiento de poder especial judicial, ofrecimiento de pruebas, solicitud de embargo y de remate, pueden plantearse de forma verbal ante la autoridad judicial respectiva.

Estas facilidades, o si se les quiere llamar beneficios, otorgadas por el constituyente a la persona trabajadora en razón de la especialización de la materia, y tomando en cuenta sobre todo el carácter social de los procesos laborales, fueron limitados con la declaratoria de inconstitucionalidad del artículo 3, inciso a) del Código Procesal Contencioso Administrativo y del numeral 402 inciso d) del Código de Trabajo, a través de los votos dictados por la Sala Constitucional, números 9928, 11034 y el 17900, del 2010. Lo anterior aplica para la persona usuaria que acuda a la jurisdicción contencioso administrativa con una pretensión relacionada con las materias de empleo público y de la seguridad social, que conlleve la nulidad del acto administrativo, pues tiene que cumplir con todas y cada una de las formalidades exigidas en el Código Procesal Contencioso Administrativo y en el Código Procesal Civil, de aplicación supletoria por disposición expresa del artículo 220 del primer cuerpo normativo citado.

Entre estos requerimientos legales pueden citarse el pago de timbres, patrocinio letrado y la presentación de copias para la contra parte. En la demanda, deberán indicarse los hechos y antecedentes del caso, especificados uno por uno, el fundamento de derecho y su elenco probatorio. Si se solicita de manera accesoria daños y perjuicios o daño moral, debe indicar el motivo que los originó, en qué consisten y su estimación prudencial. Todo lo cual, bajo apercibimiento de la declaratoria de inadmisibilidad de su demanda y el consecuente archivo del expediente (doctrina de los numerales 49, 58 y 61 del CPCA).

Como se explicó, ninguno de estos requerimientos procesales eran exigidos antes de junio del 2010 a la persona trabajadora en los casos explicados cuando acudía a la jurisdicción laboral, lo que conlleva en sí mismo, una restricción al acceso a la justicia y a la tutela judicial efectiva, derechos fundamentales derivados de los artículos 39 y 41 de la Constitución Política.

En este sentido cabe recordar que el derecho de acceso a la justicia y a la tutela judicial efectiva en el caso de Costa Rica está regulado en el artículo 41 de la Constitución Política, que expresa: "Ocurriendo a las leyes, todos han de encontrar reparación para las injurias o daños que hayan recibido en su persona, propiedad o intereses morales. Debe hacérseles justicia pronta, cumplida, sin denegación y en estricta conformidad con las leyes".

Sobre el acceso a la justicia, doctrinarios como Ciudad $(2011: 32,33)$ han expresado:

(...) el acceso efectivo a la justicia representa el derecho humano más importante en un sistema igualitario moderno que pretenda garantizar y no sólo proclamar derechos. La doctrina define el derecho de acceso a la justicia como: "El derecho de toda persona sin distinción de sexo, raza, edad, identidad sexual, ideología, política o creencias religiosas, a obtener una respuesta satisfactoria a sus necesidades jurídicas por medio de toda clase de mecanismos eficaces que permitan solucionar un conflicto (...)

Debe también señalarse que el derecho de acceso a la justicia y la tutela judicial efectiva, ha sido tratado como derecho fundamental. Sin embargo, es necesario referirse a la diferencia entre derecho fundamental y derecho humano.

Sobre el particular, Llobet (2008:124) expresa que con frecuencia se utilizan en forma indistinta los conceptos de derechos fundamentales y derechos humanos, y se llegan a considerar como sinónimos. Indica que debe tenerse en cuenta que los derechos humanos son aquellos reconocidos como tales por el Derecho Internacional de los Derechos Humanos, mientras que los derechos fundamentales son los garantizados por un Estado determinado. En un Estado de Derecho, incluso, los derechos fundamentales deberían tener un ámbito mayor que los derechos humanos, ya que deberían ir adelante en cuanto al reconocimiento de derechos que aún no han sido admitidos como tales por el Derecho Internacional de 
los Derechos Humanos, lo cual da como resultado que la lista de unos y otros nunca puede estimarse como cerrada.

En otras palabras, los derechos humanos fundamentales son vistos desde una perspectiva del derecho interno de un Estado, mientras que los derechos humanos desde la del Derecho Internacional.

Urquilla (2009:17) en torno a este debate explica:

...en materia de derechos humanos lo importante es partir de la noción de la dignidad humana como un limite para la actividad del Estado, límite que debe ser interpretado y entendido en un doble escenario, tanto como freno, en el sentido de contener el ejercicio del poder estatal, como un contenido, en el sentido de destacar que el Estado debe orientarse hacia la búsqueda de determinados propósitos. La dignidad humana, en ese sentido, marca la pauta de las actividades del Estado, sus obligaciones de hacer y de no hacer, contemporáneamente...

Sin duda alguna, el derecho de acceso a la justicia y la tutela judicial efectiva ha sido reconocido y consolidado con el transcurrir de los años como un derecho fundamental que ha permeado los más importantes y diversos instrumentos de protección universal.

La protección del derecho de acceso a la justicia ha dejado de ser un asunto de orden interno en cada país, para convertirse en un tema de importancia mundial. Toda vez que en tanto se respete, sea de forma individual o colectiva como derecho fundamental o humano, se fomentan sociedades más equitativas, justas y con mejores oportunidades para las familias, pues tratándose de reclamos contra el Estado, relacionados con el derecho al trabajo (reinstalación) o bien los derechos derivados de este, entiéndase, el pago de prestaciones laborales, permea de forma general en la sociedad.

\section{Procesos contenciosos y seguridad social}

En cuanto a la solicitud de nulidad de las actuaciones u omisiones de la Caja Costarricense del Seguro Social sobre seguridad social, entiéndase cualquier acto, conducta u omisión administrativa, que otorgue, deniegue, restrinja o suspenda una jubilación o pensión del régimen a cargo de esa institución, deberán tramitarse en la jurisdicción contencioso administrativa.

Las eventuales discusiones en vía judicial relacionadas con la seguridad social tienen índole económica, pero con un contenido específico de carácter estrictamente social en cuanto a la cobertura que brinda a la persona y su familia. Sin embargo, el juicio que eventualmente pueda plantearse en la vía contencioso administrativa o laboral para reclamar una conducta administrativa sobre algún derecho derivado de la seguridad social tiene una naturaleza con un altísimo contenido social.

Para poder entender con toda claridad esta situación Parra, Villanueva y Enrique (2008:247) comparten que:

El derecho a la seguridad social representa un instrumento de garantía del derecho de todo individuo a vivir una vida digna en aquellas situaciones de social distress como por ejemplo vejez, desempleo, enfermedades, muerte o cualquier otra circunstancia que tienda en definitiva a dificultar el goce pleno de vivir una vida con dignidad. Así mismo, es un derecho que condiciona la consecución de otros derechos humanos, como el derecho a la salud o el derecho a un nivel de vida adecuado.

El acceso sin límite e irrestricto al litigio en sede judicial relacionado con la impugnación de alguna conducta administrativa respecto a la seguridad social es tan importante, que algunos autores han llegado asegurar que dentro del Derecho del Trabajo hay una sub clasificación del llamado Derecho de la Seguridad Social.

Así Grisolia (2008b:1813), refiriéndose a la definición de esta rama especializada del derecho anota:

El derecho de la seguridad social es el conjunto de normas jurídicas que regulan la protección de las denominadas contingencias sociales, como la salud, la vejez, la desocupación. Se trata de casos de necesidad biológica y económica (...) es una rama del derecho que ampara al trabajador dependiente, al 
autónomo y también al desempleado de las contingencias de la vida que pueden disminuir la capacidad de ganancia del individuo. Se materializa mediante un conjunto de medidas y garantías adoptadas en favor de los hombres para protegerlos contra ciertos riesgos. Si bien los fines de la seguridad social no son los mismos que los del derecho del trabajo, ambos destacan por su carácter protector y por garantizar determinado nivel de subsistencia a las personas. Por lo tanto, el derecho de la seguridad social tiene un sujeto más amplio que el derecho del trabajo, ya que no sólo abarca a los trabajadores dependientes, sino que protege, además a los autónomos y a los desempleados. Es decir que los beneficiarios de la seguridad social son todos los hombres, y su objeto es amparar las necesidades que dificultan su bienestar.

Ante lo expuesto por estos autores y dada la importancia de los derechos personales y familiares derivados de la seguridad social, cabe cuestionarse si el acceso a la justicia para acatar una conducta de la Administración que haya otorgado, denegado, restringido, suspendido o modificado algún derecho relacionado, debe o no ser limitado o restringido, tomando en cuenta el impacto en el núcleo familiar, en el individuo y en la sociedad misma.

Como se explicó, al declarase la inconstitucionalidad del artículo 402, inciso d) del Código de Trabajo, cuando la parte actora solicite nulidad de las actuaciones u omisiones de la Caja Costarricense del Seguro Social sobre seguridad social, entiéndase cualquier acto, conducta u omisión administrativa, que otorgue, deniegue, restrinja o suspenda una jubilación o pensión del régimen a cargo de esa institución, debe acudir a la jurisdicción contencioso administrativa y cumplir entre los requerimientos legales, el pago de timbres, patrocinio letrado y la presentación de copias para la contra parte.

En la demanda deberán indicarse los hechos $\mathrm{y}$ antecedentes del caso, especificados uno por uno, el fundamento de derecho y su elenco probatorio. Si se solicita de manera accesoria daños y perjuicios o daño moral, se debe indicar el motivo que los originó, en qué consisten y su estimación prudencial. Todo lo cual, bajo apercibimiento de la declaratoria de inadmisibilidad de su demanda y el consecuente archivo del expediente (doctrina de los numerales 49, 58 y 61 del CPCA).

Como se explicó, ninguno de estos requerimientos procesales eran exigidos antes de junio del 2010 a la persona trabajadora que acudía a la jurisdicción laboral para solicitar la nulidad de un acto administrativo dictado por la Caja Costarricense de Seguro Social en los casos explicados. Lo anterior conlleva, en sí mismo, una restricción al acceso a la justicia y a la tutela judicial efectiva, derechos fundamentales derivados de los artículos 39 y 41 de la Constitución Política.

Finalmente, otro elemento muy importante y que también limita el derecho de acceso a la justicia a la persona usuaria que deba presentar demandas relacionadas con temas de empleo público y de la seguridad social que contengan pretensiones de nulidad, es que debe acudir Tribunal Contencioso Administrativo y Civil de Hacienda. Este tiene una única sede en todo el país, específicamente en el Segundo Circuito Judicial de San José, a diferencia de la vía laboral, cuyos despachos judiciales están asentados y distribuidos en las siete provincias, lo que evita que la persona deba trasladarse a largas distancias e incurrir en grandes gastos de dinero e inversión de tiempo.

\section{Conclusiones y recomendaciones}

- La Sala Constitucional, a partir de junio del 2010, delimitó el aspecto competencial para todas aquellas pretensiones de empleo público y seguridad social que tuvieran origen en una causal de nulidad de algún acto o conducta administrativa. Reservó el estudio y resolución por parte de los Juzgados de Trabajo, de todos los reclamos relacionados con petitorias exclusivamente patrimoniales, como es el caso de salarios caídos, vacaciones, aguinaldos, viáticos, sobresueldos, reajustes de pensión, entre otros, al declarar la inconstitucionalidad del artículo 3 inciso a) del Código Procesal Contencioso Administrativo y luego del 402 inciso d) del Código de Trabajo, disponiendo el conocimiento del 
Tribunal Contencioso Administrativo y Civil de Hacienda para esos casos anulatorios.

- Lo resuelto por la Sala Constitucional en los votos mencionados limita el derecho de acceso a la justicia y la tutela judicial efectiva. Esto es ocasionado al disponer que el Tribunal Contencioso Administrativo y Civil de Hacienda localizado en la provincia de San José, es el único que tiene competencia para conocer de los asuntos relacionados con los temas de empleo público y de la seguridad social que contengan pretensiones de nulidad.

- También se limita el derecho de acceso a la justicia a la persona usuaria, porque tratándose de asuntos relacionados con los temas de empleo público y de la seguridad social que contengan pretensiones de nulidad, la obliga a acudir a una vía en extremo formalista y que tiene una única sede en todo el país, a diferencia de la vía laboral, cuyos despachos judiciales están asentados en las siete provincias, no se exige patrocinio letrado y es gratuita.

- La limitación del acceso a la justicia es palmaria, cuando se denota que el Tribunal Contencioso Administrativo declara inadmisible una demanda porque no cumple con los requisitos de admisibilidad exigidos en el Código Procesal Contencioso Administrativo. Tal es el caso de litigar necesariamente con patrocinio letrado, el pago de timbres o bien, por no reunir la redacción del escrito de demanda, ciertas formalidades en relación a los hechos, las pretensiones, por falta de fundamentación jurídica o por el no ofrecimiento de pruebas, siendo estos los motivos más frecuentes de inadmisibilidad encontrados en el total de expedientes judiciales estudiados.

- Es evidente que la jurisdicción contencioso administrativa es mucho más costosa u onerosa para la persona usuaria desempleada (ex trabajador estatal) al no estar previstas estas exigencias procesales en el Código de Trabajo para tramitar estos asuntos en la vía laboral. Lo anterior eventualmente representará un límite de acceso a la justicia, porque deberá cubrir gastos que la legislación laboral no le imponía por tratarse de una jurisdicción gratuita.

- De esta forma, la aplicación de las reglas propias del proceso contencioso administrativo, tales como, imponer por ley requisitos que están contemplados solo en la legislación contenciosa limitan y restringen el acceso a la justicia a la persona usuaria que, tratándose de asuntos relacionados con los temas de empleo público y de la seguridad social que contengan pretensiones de nulidad, tienen que apersonarse a esta vía.

- Se produce una violación del principio protector en materia laboral, puesto que quien juzga en lo contencioso administrativo revisa únicamente la legalidad del acto administrativo impugnado, sin analizar la relación subyacente que unió a la persona (trabajador o trabajadora) con el empleador (Estado o sus instituciones), y porque no interioriza en los elementos y principios propios del Derecho del Trabajo y del Derecho Procesal Laboral y de la Seguridad Social, como lo son el in dubio pro operario, la norma más favorable o la condición más beneficiosa del trabajador, entre otros, razón de ser del Derecho del Trabajo, como forma jurídica y como expresión ideológica de la mediación entre trabajadores y patronos.

- La implicación más relevante de los votos 9928-2010, de las 15:00 horas del día 9 de junio, 11034-2010 de las 14:51 horas del 23 de junio y 17900-2010 de las 15:00 horas del 27 de octubre, todos del 2010, emitidos por la Sala Constitucional, ha sido, por los motivos expuestos, una ineludible limitación de acceso a la justicia, para aquellos usuarios y usuarias que, tratándose de asuntos relacionados con los temas de empleo público y de la seguridad social que contengan pretensiones de nulidad, tienen que apersonarse a la vía contencioso administrativo para ventilar su demanda. 
Expuestas las conclusiones, como posibles recomendaciones para que no se limite el acceso a la justicia de la persona usuaria y no hacer nugatorio el derecho a una tutela judicial efectiva, el Poder Judicial debe:

- Garantizarle al destinatario de la justicia, tratándose de asuntos de empleo público y seguridad social, tener un abogado o abogada en forma gratuita, para su representación ante los Tribunales de lo Contencioso Administrativo. De lo contrario, se quebrantarían los propios lineamientos y políticas de accesibilidad por la que ha ideado y trabajado la Corte Suprema de Justicia en los últimos años.

- De conformidad con el artículo 59, inciso 16, de la Ley Orgánica del Poder Judicial, debe crearse una jurisdicción especializada de empleo público, con un juzgado en cada cabecera de provincia, o al menos, una sección especializada en la jurisdicción contencioso administrativa, que reúna los conocimientos de las características y principios rectores de ambas jurisdicciones, con el objeto de preparar a jueces y juezas con conocimiento del derecho público y del derecho laboral, a efectos de tener una mejor formación y experiencia integral que le permitan resolver de forma equilibrada las controversias que se originan en una relación de empleo público o de seguridad social.

\section{Referencias bibliográficas}

Ciudad, Adolfo (2011). La Justicia Laboral en América Central, Panamá y República Dominicana. San José. Editorial: Organización Internacional del Trabajo.

Grisolia, Julio (2008a). Derecho del Trabajo y de la Seguridad Social. Tomo I. Décimo tercera edición ampliada y actualizada. Buenos Aires. Editorial: Abeledo Perrot.

Grisolia, Julio (2008b). Derecho del Trabajo y de la Seguridad Social. Tomo II. Décimo tercera edición ampliada y actualizada. Buenos Aires. Editorial Abeledo Perrot.
Llobet, Javier (2008). Derechos Humanos en la Justicia Penal. San José. Editorial: Jurídica Continental.

Parra, Óscar; Villanueva, María y Agustín, Enrique (2008). Protección Internacional de los Derechos Económicos, Sociales y Culturales. Sistema Universal y Sistema Interamericano. San José. Editorial: Instituto Interamericano de Derechos Humanos.

Urquilla, Carlos (2009). Derechos Humanos en la agenda de población y desarrollo. Vínculos conceptuales y jurídicos, estándares de aplicación. San José. Editorial: Instituto Interamericano de Derechos Humanos.

\section{Leyes:}

Constitución Política de Costa Rica, 7 de noviembre de 1949.

Costa Rica, Código de Trabajo, Ley $N^{\circ} 2$ del 29 de agosto de 1943.

Costa Rica, Código Procesal Contencioso Administrativo, Ley No 8508 del 28 de abril del 2006.

Costa Rica, Ley Reguladora de la Jurisdicción Contencioso Administrativa N $^{\circ} 3667$ del 1 de marzo de 1966

\section{Pronunciamientos de órganos jurisdiccionales consultados:}

Costa Rica, Sala Constitucional. Sentencia Nº 3905-94 del 3 de agosto de 1994.

Costa Rica, Sala Constitucional. Sentencia No 5686-95 del 18 de octubre de 1995.

Costa Rica, Sala Constitucional. Sentencia Nº 14999 del 16 de octubre de 2007

Costa Rica, Sala Constitucional. Sentencia N 9928-2010 del 6 de junio de 2010

Costa Rica, Sala Constitucional. Sentencia N ${ }^{\circ} 11034-2010$ del 23 de junio de 2010.

Costa Rica, Sala Constitucional. Sentencia No 17900-2010 del 27 de octubre del 2010

Costa Rica, Sala Primera. Resolución 1271-C-S1-2010, del 21 de octubre del 2010

Costa Rica, Sala Primera. Resolución 00952-C-S1-2011 del 11 de agosto del 2010. 


\section{Hipervínculos}

http://portal.poder-judicial.go.cr/accesoalajusticia/index.php/documentacion

htHYPERLINK "http://portal.poder-judicial.go.cr/accesoalajusticia/index.php/documentacion?start=20"

tHYPERLINK "http://portal.poder-judicial.go.cr/accesoalajusticia/index.php/documentacion?start=20”

p://HYPERLINK "http://portal.poder-judicial.go.cr/accesoalajusticia/index.php/documentacion?start=20"

pHYPERLINK “http://portal.poder-judicial.go.cr/accesoalajusticia/index.php/documentacion?start=20”ortal.poder-judicial. go.cr/accesoalajusticia/index.php/documentacion?start $=20$ 